\title{
Orientation and Function of Examination Evaluation in the Reform of College Entrance Examination
}

\author{
Tong Liu* \\ Heilongjiang Enrollment and Examination Institute, Harbin 150001, China \\ *Corresponding author: Tong Liu, liutong_1215@126.com
}

\begin{abstract}
With the aim of deepening the college entrance examination reform, this paper analyzes the orientation and role of examination evaluation in the reform of college entrance examination. Firstly, the paper expounds the implementation of the college entrance examination reform and affirms the necessity of several related educational reforms. Secondly, it expounds the orientation of examination evaluation. Finally, it summarizes the function of examination evaluation from four aspects: guiding the development of students' comprehensive quality, supervising teaching work, promoting the progress of teaching work, and guiding examination propositions. The advantages of examination evaluation are emphasized to promote the reform of college entrance examination and further drive the progress of the education reform in China.
\end{abstract}

Keywords: College entrance examination reform; Examination evaluation; High quality education system; Academic proficiency test

Publication date: August 2021; Online publication: August 30, 2021

\section{Introduction}

The Central Committee of the Chinese Communist Party (CPC) and the State Council issued the Overall Plan for Deepening the Reform of Education Evaluation in the New Era on October 13, 2020, which emphasized on the importance of forming national education examination teams and professional education examination institutions. Since the reform of the college entrance examination, various regions have proposed relevant reform plans while adhering to the socialist way of managing schools under the guidance of the Party's education policy. In addition, they have also improved the educational evaluation system according to the reform practice of college entrance examination. For example, in response to the reform of Shanghai's college entrance examination, the orientation and role of examination evaluation are analyzed, and meetings are organized in order to share basic theories and practical experiences from the reform. Entering a new stage of social development, the college entrance examination system needs to be innovated along with the development trends of the times. It is not sufficient to only meet the requirements of the college entrance examination in the new era, but also necessary to create a new pattern of college entrance examination to achieve the goal of education modernization.

\section{Reform of the college entrance examination}

In the new era, new requirements have been put forward for a high-quality education system. These new requirements are predominantly seen in the reform of the high school entrance examination and the college entrance examination. It is mandatory that the academic level examination in junior high schools and senior high schools are continuously being improved. The education examination institution is responsible for the 
reform and strengthening of professionalism and standardization of examination development technology, examination organization mode, as well as examination evaluation ${ }^{[1]}$. The Overall Plan for Deepening the Reform of Educational Evaluation in the New Era also propounded, "Adhere to scientificity and effectivity, improve the result evaluation, strengthen the process evaluation, explore value-added evaluation, improve in comprehensive evaluation, make full use of information technology, as well as improve the objective of educational evaluation." In regard to education examination organizations in the reform of college entrance examination, specific content innovation, team building, professional services, and other layers can widen the evaluation pathway while supporting students to achieve an all-rounded development in the reform of the current characteristics as well as the provision of Chinese characteristics in the education evaluation system $^{[2]}$.

As early as 2014, the State Council issued the Implementation Opinions on Deepening the Reform of the Examination and Enrollment System, in which it was the beginning of the college entrance examination reform. At the same time, the education department also issued a succession of related documents, which covered four aspects: the academic level examination, comprehensive quality evaluations, additional points for college entrance examinations, as well as independent enrollment for colleges and universities. With the support of the above documents, the reform of the enrollment system has a reference, and the education reform officially entered a new period ${ }^{[3]}$. In addition, since the Third Plenary Session of the $18^{\text {th }}$ CPC Central Committee, the Decision of the CPC Central Committee on Several Major Issues Concerning Comprehensively Deepening the Reform has been implemented in the field of education. The selection and evaluation system, training system, as well as the concept of educational examination have been innovated in order to realize the development of the majority of students in terms of their comprehensive quality.

\section{Orientation of examination evaluation in the reform of college entrance examination}

Under the influence of a combination of various disciplines, basic theory, and the gradual achievement of technology innovation, modern statistical science, education, and psychological measurement, the modern examination evaluation concept is formed. It is widely applied in the field of education at the present stage, and it is also accepted by teachers after recognizing that the evaluation results are able to monitor the quality of teaching and the learning progress of students. In order to meet the requirements of the college entrance examination reform, a special examination evaluation and education monitoring department has been formed. This department is responsible for educational administrative decision-making, innovating educational teaching models, and determining examination propositions, in which this department has achieved ideal benefits in the social environment. In the implementation process of the reform, a perfect scheme has been summed up to guide the targeted education work. In examination evaluation, innovation should be achieved by the virtue of technology to promote the effective link between the examination and enrollment, as well as teaching and the comprehensive development of students in the future ${ }^{[4]}$.

There are many aspects that need to be considered in regard to the orientation of examination evaluation in the reform of college entrance examination. As China's education enters the era of popularization, although the enrollment scale of various universities is relatively large, the college entrance examination still faces some issues that need to be solved in all sectors of the society. The examination itself is fair, objective, and has an extremely high efficiency in the selection and assessment of talents. It is also an effective test for the quality standards of education and teaching. However, it may not have a real-time comprehensive test range. There would be a certain skewness if it is just based on students' evaluation on the test results. Without effective feedback information on the examination, education institutions would not be able to determine the education quality or conclude the value from the teaching results.

The reform of the examination and enrollment system attaches more importance to the comprehensive evaluation of the examinees, innovation of evaluation technologies, as well as the transformation of the 
examination and evaluation concept. Student evaluation is not only multidimensional, but also includes the element of objectivity, which is an important prerequisite for the comprehensive implementation of qualityoriented education. Scientific rationality is enhanced as the scope of examination evaluation expand, in which the resulting refines the evaluation results, thus evaluation gradually becomes the medium between teaching and examination, and at the same time, students are responsible for the evaluation of the examination results, which can also be found in daily teachings, examinations, and learning issues ${ }^{[5]}$.

\section{Role of examination evaluation in the reform of college entrance examination}

\subsection{Guiding the development of students' comprehensive quality}

The Opinions on Deepening the Reform of the Examination and Enrollment System has been implemented in the reform of college entrance examination, in which universities began to change from a single choice to two-way interactive choice. As students have two academic level exams and three disciplines are chosen in view of the academic test scores as the entrance exam score, the focus of entrance exams and academic level exams are on general subject knowledge. After school level examinations, students would know more about their individual abilities and look for professions which are suitable for them. With the revisions of "new curriculum standard" and "academic level standard," subject knowledge and ability have become more specific and detailed, in which they are the key basis for examination evaluation. Students can then choose their majors after a comprehensive analysis. In the future, examination evaluation would also provide academic diagnosis reports after the comprehensive analysis of previous examination results in order to help candidates understand their strengths and problems from two aspects, which are subject knowledge and comprehensive ability, as well as guide the development of students' comprehensive quality.

Facing the implementation of the college entrance examination reform, the class-selection system has been implemented. With this system, students would study in different classes in a hierarchical way, which truly realizes teaching in accordance with students' aptitude. However, some teachers believe that the system would elevate the pressure of studying among students. In essence, schools take into account the physical and mental differences among students. With optimized allocation of educational resources, schools can eventually accentuate students' strengths and help them overcome their weaknesses in respect to students' individualized development. In view of the class-selection system, students can choose their own classes according to their needs, and examination evaluation technology is more targeted. Subject knowledge is taken as a carrier to improve subject ability. If conditions permit, big data technology can also be used for analysis to determine the orientation of students' subject ability and subject knowledge.

\subsection{Supervising teaching work}

The test-oriented education and assessment system, which have been long formed, have a dual impact on education work. According to relevant requirements of the college entrance examination reform, it is possible to change the prevailing test-oriented education but may not completely eliminate the phenomenon of students' informal liberal arts and science subjects. For this, in the implementation of the reform, test evaluation should be used for teaching supervision in three levels, which involve the national, provincial, and municipal levels, in order to improve the supervision system for quality education. In view of the academic proficiency test, there is a need to consider the conduct of reasonable evaluation work, apply data mining technology, analysis, and test data in the teaching of valuable information, summarize the issues that are faced by the teaching work at present stage, improve the quality of teaching work and the learning ability of students under the supervision of examination evaluation. 


\subsection{Promoting the progress of school teaching}

The reform of the examination and enrollment system has been placed on the agenda in succession to the implementation of the college entrance examination reform. After the reform, the enrollment system is much more diversified, and students have more opportunities to show themselves and determine their own shortcomings. For schools, data can also be analyzed after examination evaluation to understand the problems faced in the teaching work ${ }^{[6]}$. The performance of one test is taken as the subject in the traditional form of examination evaluation; in addition, there is inadequate emphasis on the changes in schools and students. As the statistical analysis method is single, minimal attention is paid to students' follow-up learning. Along with the in-depth implementation of the reform, the learning process of students and subject development have attracted great attention. Examination evaluation has begun to attach importance to longitudinal data. Moreover, previous evaluation methods in averaging scores and graduation rates have been innovated to ensure the fairness and rationality of examination evaluation. By longitudinal evaluation, teachers and schools do not only focus on the changes among top students, but also all students and groups to promote the progress of each student. Test scores are taken as the standard in longitudinal evaluation; data link and selection are more emphasized and invalid data are screened on time to avoid interference to the final analysis results. In regard to the application of test data, at times, there are long intervals before the test; hence, it is important to strengthen the reliability of the data connection among candidates. Based on the comprehensive evaluation of multiple dimensions and subjects, the progress of school teaching can then be promoted.

\subsection{Guiding the examination proposition}

In the reform of college entrance examination, examination evaluation plays a role in improving the proposition. Generally, after examination evaluation, the advantages and disadvantages of the questions are found, the validity and reliability of the questions themselves are strengthened, and the agreement between important indexes, such as the degree of differentiation and examination requirements, can be closely linked. In actual situations, the reform of the examination and enrollment system has offered students many opportunities to participate in academic level examinations and foreign language examinations, in hope to improve students' comprehensive quality. In this way, they would be able to choose their future majors according to their strengths and advantages. Including the departmental related content from the reform of liberal arts college entrance examination, high school examinations may exist in the form of educational level exam. Students would choose three scores for the university entrance exam with the academic level exam having the selection function while considering the difficulty of the academic proficiency test for proposition institutions and the degree of differentiation. Before the reform, the examination was used as the basis to measure the graduation standards among students, and the proposition only required that the mastery of subject knowledge and basic ability are examined. However, the proposition of the academic level examination required that the issues related to the selection function should be solved, thus examination evaluation and analysis results have to be used.

Test data are extremely necessary. In terms of the distribution of student achievement, subject characteristics, and knowledge structure, the propositions of all disciplines should conform to the new curriculum standard along with the content knowledge from teaching materials and ability structure, which are divided in the reform of college entrance examination under the background that the adjustments of the scientific examination evaluation system and the evaluation itself require a standard of reference that is extensively based on the examination education reform. In this way, the quality of students and their overall ability can be promoted. 


\section{Conclusion}

In summary, it is not difficult to appreciate that examination evaluation plays an extremely important role in the implementation of the college entrance examination reform. It is mainly manifested in guiding students' development, teaching, examination proposition, and other aspects. In the present education environment, it is fairly necessary and urgent for the reform of college entrance examination in order to change the traditional idea. Relying on the test evaluation summary, suggestions on teaching and the progress of students, on the one hand, are able to boost the development of quality education in the country, and on the other hand, they also help to realize the comprehensive development of students in the new environment.

\section{Disclosure statement}

The author declares that there is no conflict of interest.

\section{References}

[1] Fan Y, Xu H, Zhao P, 2019, The Dilemma and Breakthrough Strategy of Comprehensive Quality Evaluation in the New College Entrance Examination Reform. China Examination, 000(007): 63-71.

[2] Yu H, 2019, A New Era of College Entrance Examination and Content Reform Implementation Path. Chinese Examination, 000(001): 1-9.

[3] Ren Z, Zhao X, Chen A, 2019, Deepening the Reform of College Entrance Examination Content and Boosting the Development of Quality-Oriented Education - Key Problems and Solutions in the New College Entrance Examination Reform. China Higher Education Research, 305(01): 42-6.

[4] Jiang G, 2019, Play the Guiding Role of College Entrance Examination Content Reform to Promote Education Evaluation Reform. Chinese Journal of Examinations, 326(06): 4-7.

[5] Yang G, 2019, The Value Orientation of College Entrance Examination Subject Setting in Comprehensive Reform. Hubei Education (Government Affairs publicity), (2).

[6] Yang G, 2019, The Value Orientation of College Entrance Examination Subject Setting in the Comprehensive Reform of College Entrance Examination. Hubei Education Comprehensive Information, 000(002): 68-9. 